\title{
Factors That Influence Healthcare Professionals' Online Interaction in a Virtual Community of Practice
}

\author{
Faith Ikioda $^{1}$, Sally Kendall ${ }^{1}$, Fiona Brooks ${ }^{1}$, Anna De Liddo ${ }^{2}$, Simon Buckingham Shum ${ }^{2}$ \\ ${ }^{1}$ Centre for Research in Primary and Community Care, University of Hertfordshire, Hatfield, UK \\ ${ }^{2}$ Knowledge Media Institute, Open University, Milton Keynes, UK \\ Email: f.ikioda@herts.ac.uk
}

Received July 14, 2013; revised August 20, 2013; accepted October 8, 2013

Copyright (C) 2013 Faith Ikioda et al. This is an open access article distributed under the Creative Commons Attribution License, which permits unrestricted use, distribution, and reproduction in any medium, provided the original work is properly cited.

\begin{abstract}
Online technologies have facilitated the development of Virtual Communities of Practice (virtual CoPs) to support health professionals collaborate online to share knowledge, improve performance and support the spread of innovation and best practices. Research, however, shows that many virtual CoPs do not achieve their expected potential because online interaction among healthcare professionals is generally low. Focusing on health visitors, who are UK qualified midwives or nurses who have undertaken additional qualifications as specialist public health workers in the community, the paper examines the factors that influence online interaction among health visitors collaborating to share knowledge and experience in a virtual CoP. The paper makes suggestions for how to improve online interaction among health professionals in virtual CoPs by increasing the size of membership in order to take advantage of both posting and viewing contributions, facilitating moderation to improve networking among geographically dispersed members groups and improving the topic relevance in order to stimulate contributions.
\end{abstract}

Keywords: Virtual Community of Practice; Health Visitors; Online Interaction; Collaboration

\section{Introduction}

Health professionals including practitioners, government agencies and policy makers, often work with different perspectives of knowledge within and across diverse organisations with aim of improving healthcare practice. Developing processes of collective sense making across these various stakeholders in order to reconcile divergent perspectives of knowledge and standardize best practices requires that ways of enhancing interagency collaboration are facilitated [1,2].

In recent years, varying forms of online technologies have been employed to support collaborative knowledge sharing and learning within and between groups of health professionals in order to improve standardization and spread of best practices. One strategy that has been increasingly employed to foster collective sense making and improve shared decision among health professionals has been promoted through the development of Virtual Communities of Practice (virtual CoPs).

Virtual CoPs primarily describe a network of individuals who share a domain of interest about which they communicate and share experiences, problems and solutions online, with the aim of improving the knowledge of each participant and the overall domain [3]. Virtual CoPs support interaction, collaboration and learning among professionals especially where face-to-face interactions are limited due to geographic spread, organizational boundaries, costs and time difference. Studies in health research reveal that virtual CoPs potentially support and enhance how healthcare teams that may not normally work together might use online interaction to collaborate in order to share, debate, resolve, integrate and implement different perspectives on practice to improve and inform evidence-based decision making.

Virtual CoPs have also been noted as being capable of extending healthcare practitioners' learning beyond faceto-face opportunities by promoting distributed and continued learning [4,5]. Others studies have also explored how collaborative conversations in virtual CoPs can help to strengthen intra-professional ties, enhance information access and improve support that would otherwise be unavailable to healthcare teams [6].

Despite evidence revealing that virtual CoPs can improve informal peer support and networking, improve shared decision making and overcome professional isolation amongst geographically dispersed teams of health 
professionals, research also suggests that many virtual CoPs developed for health professionals fail because rates of online interaction are often very low [7]. But little is known about the extent to which patterns of online interaction among health professionals are influenced by the cognitive, social and material structures that are present in the virtual CoP [8]. Online interaction may, for instance, be conditioned by whether an organization sanctions the use of a virtual CoP by its employees in view of its potential for improving practice, whether members feel their contribution is important and useful to share and whether members trust that the information being collectively shared in the community is not misleading or overtly critical [9,10]. In addition, busy schedules, topic relevance of the online community, ICT literacy of participants, presence or lack of moderation and appropriate tasks to enhance participation, lack of feedback/responses to posts and forgotten passwords and usernames, can all have an effect on online interaction.

Dubé et al. [11] collectively describe these aforementioned factors as the structuring characteristics of a VCoP which are defined as those stable elements that can be used to describe an Online CoP at a particular point in time. The structuring characteristics of a virtual CoP include its demographics (lifespan, age, maturity and orientation of the community), its organizational context (creation process, degree of institutionalized formalism), its membership (size, geographic dispersion, enrolment, topic relevance, prior community experience, stability, selection process, diversity) and its technological environment (Table 1). Until now, the relationship between the structuring characteristics of virtual CoPs as they relate to explaining low rates of online interaction among health professionals has been unexplored. Most studies exploring virtual CoPs in health research have been primarily descriptive and have sometimes lacked a sound theoretical development of the structuring characteristics underpinning the virtual CoP model [12]. In exploring how the structuring characteristics of a virtual CoP may influence online interaction among health professionals, this paper employs initial findings from a study of a virtual CoP developed for health visitors, to considers how the group size (including the members' stability), topic relevance and geographic dispersion (including prior community experience and group's diversity) influence rates of online interaction.

\section{About the Project}

\subsection{The Health Visitors' Virtual CoP}

Health visitors are UK qualified midwives and nurses who have taken on additional qualifications to become community public health nurses working with children and families [13]. In the UK, they are considered to play a strategic role in the promotion of child and family health and the prevention and detection of problems in early childhood. Policy agenda has in recent years focused on how to regain leadership and develop professsional autonomy in health visiting practice in order to improve the health of families and children [14].

Improving joint working by allowing health visitors articulate collate and verify the range of knowledge drawn from professional experience and research evidence presents one way to improve health visiting practice [15]. Mobile working arrangements, widely varying organizational targets, time-pressures and geographic dispersion limit the opportunities for health visitors to collaborate with peers to collectively articulate and share the knowledge applied to professional and clinical judgments.

The study therefore involved a pilot research project designed to explore the potential of a virtual CoP to empower health visitors in order to provide health visitors with an opportunity to collectively collaborate in a virtual space in order to improve and standardize best practice. The online platform, called the Health Visitors' Community of Practice Evidence Hub (HV-CoP hereafter) [16], allowed health visitors to articulate professional knowledge to support and implement evidence-based practice via a variety of asynchronous activities including:

- Posing an issue that explores a concern emerging from practice.

- Suggesting a good practice point that helps to re-solve an issue posted.

- Signposting relevant evidence that supports suggested good practice in the forms of specific case studies and stories, guidelines, policy documents, research findings, evaluations, reports and various tool kits.

- Signposting online resources that advance and support everyday practice.

- Providing the opportunity to comment, follow issues, promote or demote evidence.

Through this virtual space, health visitors collectively articulated common issues arising from everyday experience and weighed professional suggestions for best practice against these issues using evidence from professional practice as well as policy, guidelines and checklists to support their contributions (Figure 1).

\subsection{Participants in the Project}

The Health visitors who took part in the study were recruited from two pilot study areas in the South of England. Information about the project was communicated via managers, to recruit health visitors in their localities to attend a series of training sessions/seminars on using a virtual platform to share best practices. 
Table 1. Characteristics of the health visitor's virtual CoP.

\begin{tabular}{|c|c|c|}
\hline Dimensions & & Health Visitors Online CoP \\
\hline \multirow[t]{3}{*}{ Demographics } & Age & 1 year \\
\hline & Life Span & $\begin{array}{l}\text { Permanent- and on-going mechanism for knowledge sharing among health } \\
\text { visitors in the long-term }\end{array}$ \\
\hline & Stability & Membership was open to all health visitors in two pilot areas \\
\hline Context & Creation Process & Research project (top-down) \\
\hline \multirow[t]{6}{*}{ Membership } & Size & Large ( $>100$ health visitors) \\
\hline & Geographic dispersion & Medium (spread across two localities) \\
\hline & Enrolment & Voluntary \\
\hline & Diversity & $\begin{array}{l}\text { High (student health visitors, practice mentor teachers, health } \\
\text { visitor academics) }\end{array}$ \\
\hline & Fluidity/Stability & New members can join anytime \\
\hline & Prior Community experience & $\begin{array}{l}\text { Low (the health visitors did not know each other nor had they worked } \\
\text { together prior to joining the virtual community) }\end{array}$ \\
\hline Technological environment & Degree of reliance on technology & High (used a website) and elements of offline facilitation \\
\hline Moderation & Moderated or not moderated & Moderated \\
\hline
\end{tabular}

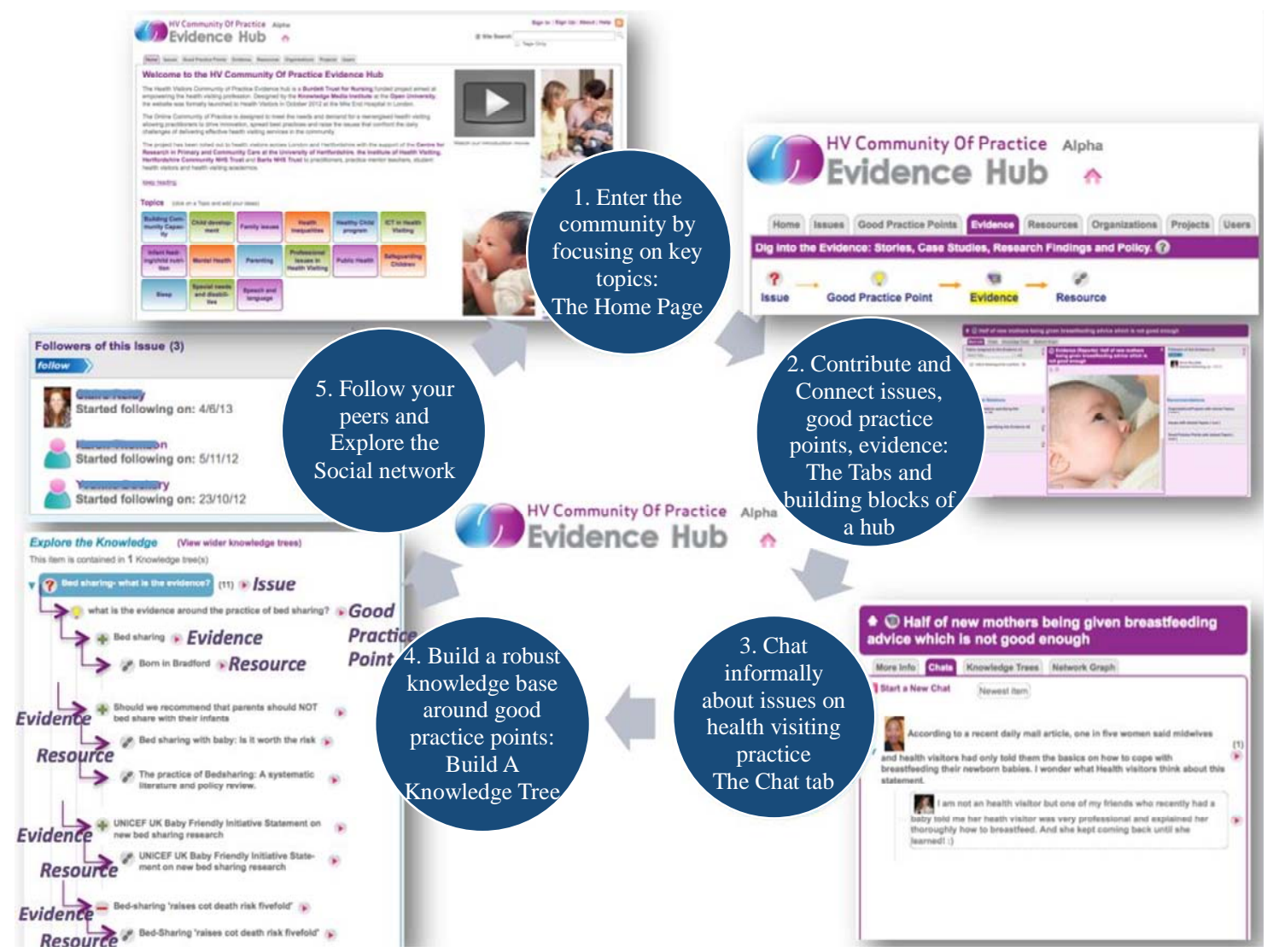

Figure 1. The health visitors virtual CoP.

McCartney et al. [17] note that a practical consideration to have in mind with virtual CoPs for health professionals is the need to ensure that potential members have the necessary skills training and understand the features of the virtual environment in order to use it effectively. As part of the training sessions, facilitation activities, including follow up seminars, a quick guide booklet for using the platform and publishing newsletters highlighting updates from the community, were regularly disseminated to participants.

Xie and Bradshaw [18] have argued that presence of moderation and guidance, as demonstrated via these or- 
ganized sessions and supporting materials, can facilitate interaction in large collaborative situations where participants are distributed widely. Other studies have shown that facilitation can be essential because it encourages participants to connect through group tasks to generate information which can be used to seed discussions, which keeps the community vibrant [19].

For each health visitor who volunteered to participate in the study, a record was set up via the website of their basic characteristics. This record included the name, location, current role, date of joined, last log in, number and type of contributions and topics contributed to. This data collated from the website forms the basis of the discussion that follows.

\section{Some Factors Influencing Health Visitors Online Interaction in the HV-CoP}

\subsection{The Influence of Number of Participants in the HV-CoP on Online Interaction}

In previous studies of virtual CoPs in health research, research has tended to focus on pockets of qualitative studies that studied random groups collaborating over very short periods of time [20]. Consequently, it has been difficult to interpret how the relationship between the life-cycle, age, stability of membership and in particular the number of participants affects online interaction for health professionals collaborating virtually.

Based on the health visitors who registered to the HV$\mathrm{CoP}$ in the course of the first year, the analysis revealed that overall online contributions of posts in-creased overtime as new members joined. As more health visitors joined new issues, good practice points, comments and resources to support existing and previously posted evidence pieces were added and re-energized posting activi- ties in the HV-CoP. Contributions and overall participation of health visitors tended to stagnate until new members joined and re-invigorated the discussion in the community by seeding new discussions and providing new responses through good practice points to previously posted issues (Figure 2).

The size of the group has a strong relationship with the stability of membership when considering the effect of member numbers on online interaction. So long as the community continues to allow new members to join it and does not restrict or close its membership to a selected cohort of participants, there is an increased chance that the community will thrive because new discussions and suggestions will be added by potentially more enthusiastic newcomers [21].

Literature suggests that virtual CoPs are composed of both observers, who are persons still considering whether the community is a right fit for them, as well as participants, who have begun to reflect on what they have to contribute to the community [22]. Blanchard and Markus [23] further identify two types of distinctive online participants in virtual environments. There are active participants who embrace activities related to posting and responding to messages and passive participants who primarily focus on the reading of messages. Wang and $\mathrm{Yu}$ [24] use the term lurkers to classify participants who not only just read posts but also to apply to those observers who may not be ready to join the community yet.

In essence, these discussions allude to the fact that any virtual CoP is likely to be composed to varying degrees with lurkers, observers, passive and active contributors. More particularly, because online interaction is often measured by who contributes, post questions and provides feedback at the expense of other types of behavior, like reading and viewing posts, having a high number of

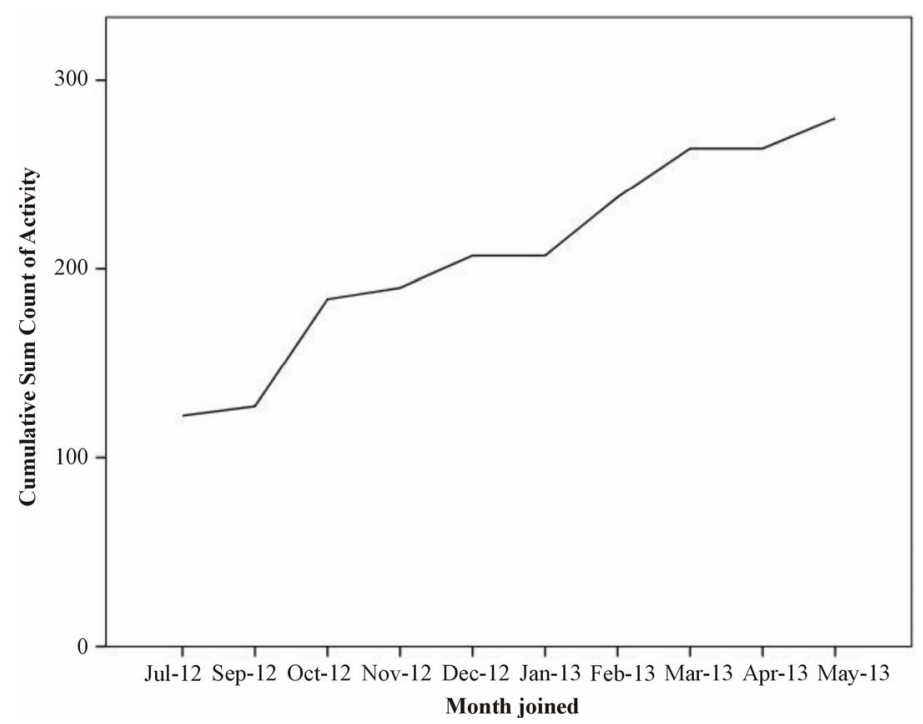

Figure 2. Cumulative count of contributions by new joiners each month from July 2012-May 2013. 
lurkers/observers and passive contributors (when compared to active contributors) who read but do not post may translate to mean that online interaction is low [24].

In analyzing varying engagement in the HV-CoP, passive contributors referred to health visitors who since joining the virtual CoP have never made a posting contribution, while active contributors referred to health visitors who had at least made one posting contribution since joining. Lurkers/observers indicated health visitors who visited the HV-CoP website and viewed pages but did not formally register to join the virtual community as members. From the analysis, subtracting the 106 health visitors who joined the HV-CoP (Table 2) from the 278 people who visited the website in its first year (Figure 3), 172 lurkers/observers had visited the HV-CoP website to view pages without joining as participants.

Keeping membership fluid in order to attract new members, rather than being stable and limiting or restricting membership, may be necessary to compensate and ameliorate for the effect of "participation inequality" [25]. Work on participation inequality in internet culture notes that it is common to observe a 90-9-1 rule where $90 \%$ of lurkers, $9 \%$ of contributors who post from time to time and $1 \%$ who post very often, comprise online interaction in large communities [25]. Despite exhibiting a higher than average rate of participation inequality with 80 health visitors (28\% of all visits to the HV-CoP) making a posting to website, the remainder $71.2 \%$ of lurkers/observers and passive contributors viewing and reading posts suggests that online interaction (as measured by posting) appears rather low among health visitors. The need to keep membership open and fluid, rather than static and restricted to a few persons, should be considered because not all members who join a virtual CoP pull their weight and contribute actively. Since lurkers, observers, active and passive contributors all increase proportionally overtime, virtual CoPs must continue to aim to welcome potentially enthusiastic new members to sustain posting contributions and to counter the effect of lurkers and passive members.

Although an increase in the critical mass of users using in a virtual CoP may maximize the positive contributions of enthusiastic members and minimize the reading activities of lurkers, research has also shown that an increasing number of users in a virtual $\mathrm{CoP}$ alone will increase online interaction. This is because new members will join a virtual $\mathrm{CoP}$ because they associate a substantial number of people using a virtual $\mathrm{CoP}$ with a thriving community even when no immediate benefits from contributions are apparent [26]. Encouraging posting contributions may therefore not be the only way to explore how health professionals interact online. Wang and $\mathrm{Wu}$ [24] and Ardichvili, et al. [10] have for instance mentioned that postings represents only one side of the vibrancy of a Virtual
$\mathrm{CoP}$ and suggest other ways of depicting online interacttion, like considering whether people are visiting the virtual CoP.

Between October 2012 and December 2012, there were 139 posts made on the HV-COP (Table 3). In the same period however, a total of 4166 pages were viewed by health visitors (Figure 4). Thus while considerably fewer than posting contributions, the higher viewing figures show that reading and viewing posts may play a much more important role than previously considered role in explaining online interaction. Overall, logging onto the HV-CoP website to read and view posts, follow other health visitors' activities, vote on comments or editing user profiles, all showed that health visitors still interacted online even when they were not posting.

\subsection{The Influence of Geographic Dispersion of Health Professional on Online Interaction}

One of the advantages for employing a virtual CoPs is the capability to support interaction among professionals who may not normally work together (due to geographical dispersion and other organizational limitations) to collaborate and share expertise. But often this very character of geographic distribution as well as other forms of diversity among professionals which developing a virtual $\mathrm{CoP}$ aims to ameliorate, can in itself negate online interaction that is necessary for the success of collaborating virtually.

The health visitors in this study worked across two localities and were based in different clinics and worked under very different organizational settings. Hence, except for a handful or members, there was little previous interaction amongst the health visitors prior to participating in the HV-CoP. In addition, health visitors who participated in the online community displayed a mixture

Table 2. Characteristics of participants' behavior in the HV-CoP.

\begin{tabular}{cccc}
\hline Period & $\begin{array}{c}\text { Joined } \\
\text { (participants) }\end{array}$ & $\begin{array}{c}\text { Active } \\
\text { Contributors }\end{array}$ & $\begin{array}{c}\text { Passive } \\
\text { Contributors }\end{array}$ \\
\hline July-October 2012 & 30 & 21 & 9 \\
$\begin{array}{c}\text { November 2012- } \\
\text { February 2013 } \\
\text { March 2013- } \\
\text { June 2013 }\end{array}$ & 74 & 50 & 24 \\
\hline
\end{tabular}

Table 3. Posting contribution per month on the HV-CoP.

\begin{tabular}{cc}
\hline Month & Monthly Total contributions \\
\hline October 12 & $\mathbf{6 6}$ \\
November 12 & $\mathbf{2 0}$ \\
December 12 & $\mathbf{5 3}$ \\
Total & $\mathbf{1 3 9}$ \\
\hline
\end{tabular}




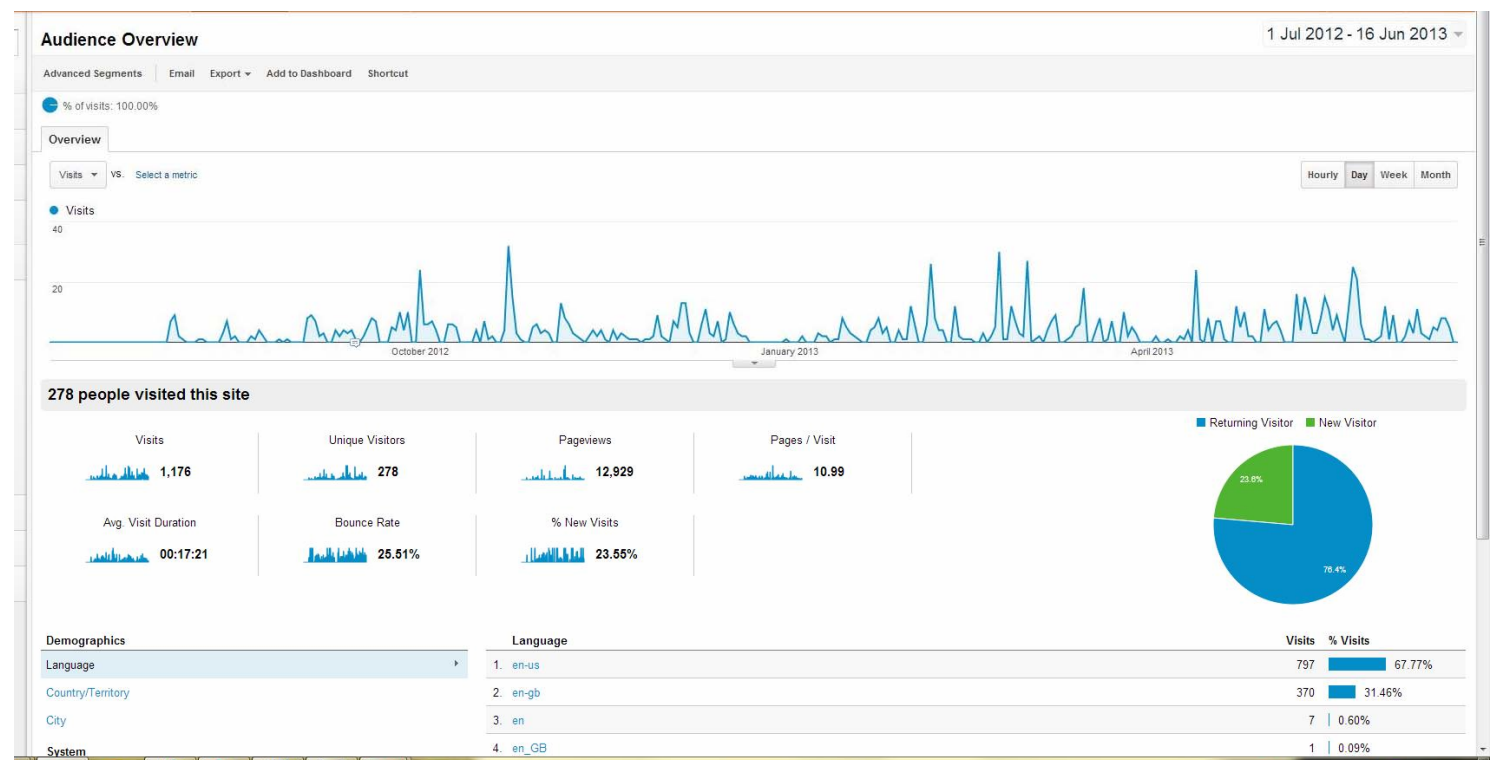

Figure 3. Google analytics audience overview for the health visitors HV-CoP over the period of one year.

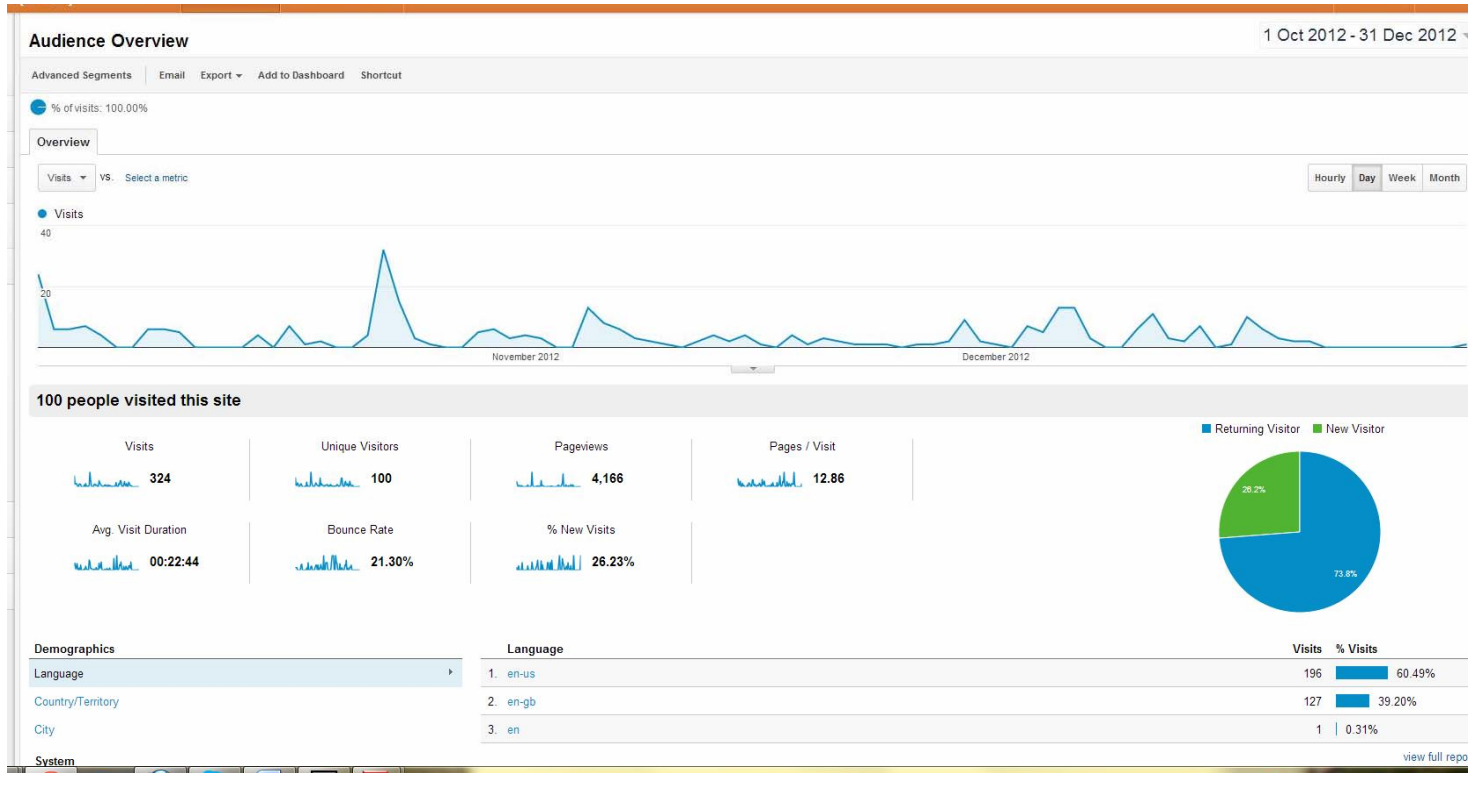

Figure 4. Google analytics of audience overview for the HV-COP between October 2012 and December 2012.

of professional roles, including students in training, newly qualified health visitors, experienced practitioners, practice mentor teachers and academics; and all collectively displayed considerable variation in their depth and expertise in knowledge sharing virtually.

It has been noted elsewhere that a potential issue with online and computer-mediated communications is that it is less personal and often diminishes social presence and cues present in face-to-face communication [27]. As a result, fewer cues lower social presence lowers the sense of community, which in turn can be especially problematic for interaction among distributed groups with little or no prior connection. The sense of community depicted by the feelings that members have of "belonging" that is required is to help to sustain the common perspective that knowledge is a public good, owned and maintained by the community [28] is therefore potentially absent in a virtual CoP and can greatly influence whether or not interaction develops online.

In this study, with such a high diversity of health visitors coupled with working across two geographical regions and limited prior social connections, establishing a common vision for the group to coalesce to support online interaction was paramount. Because a strong community feeling was likely to be absent due to the geographically dispersed working arrangements of the health 
visitors, there was the added pressure to engineer a sense of community among the members by clarifying shared values and goals so as to facilitate online interaction.

Although the virtual CoP's website was the main technology employed by the health visitors to interact, a further 8 offline meetings to introduce how to use the website to the health visitors were conducted throughout the first year of the project. Facilitated by a moderator, these offline meetings consisted of three-hour sessions for new health visitors joining the HV-CoP to undertake group tasks collectively in order to foster sense of community whilst learning to use the web interface. Koh et al. [29] have argued that some element of offline participation is integral to facilitating posting activities in virtual CoPs as a way of encouraging a sense of social presence crucial to its success.

To explore the influence that geographical dispersion, diversity of participants and moderation had on whether a sense of community had gradually developed among the health visitors as they interacted in the HV-CoP, a social network map was produced (Figure 4). Social network analysis suggests that the greatest connection in the network indicates a greater chance of a sense of community and greater online interaction that is capable of supporting resource exchange among practitioners [30]. It has been acknowledged that social network analysis is a useful way to examine whether professional connections and relationships are being developed by health practitioners as they interact and share knowledge in a virtual

\section{CoP [31].}

The results from the social network map revealed whether health visitors had established connections by responding to a post by another health visitor by reciprocating a posting with a good practice, online resource or supporting evidence. The social network showed that the greatest density of interactions in the social network was observed around health visitors replying to and making connections to the issues seeded by the community's moderator to facilitate initial discussion. The analysis corroborates work that suggests that the moderator may be the single most important point in a network, whose departure or absence may result in the break of flow of information and interaction [31]. Fontaine [19] has argued that it is the moderator or facilitator's role to choose to seed discussions where possible in order to keep online interaction vibrant and to ensure that networks and connections are developed by community members. In large distributed groups inter-acting online, a lack of moderation increases the possibility of having unconnected networks since participants may be too different and lack the social awareness and trust to develop connections around a shared perspective. The potential for unconnected relations to develop amidst the diversity of members is highlighted from the social network of health visitors interacting in the $\mathrm{HV}$-CoP, despite the moderation (Figure 5). Aside from the larger network of health visitors connected directly and indirectly to the moderator IN the social network, unconnected and isolated

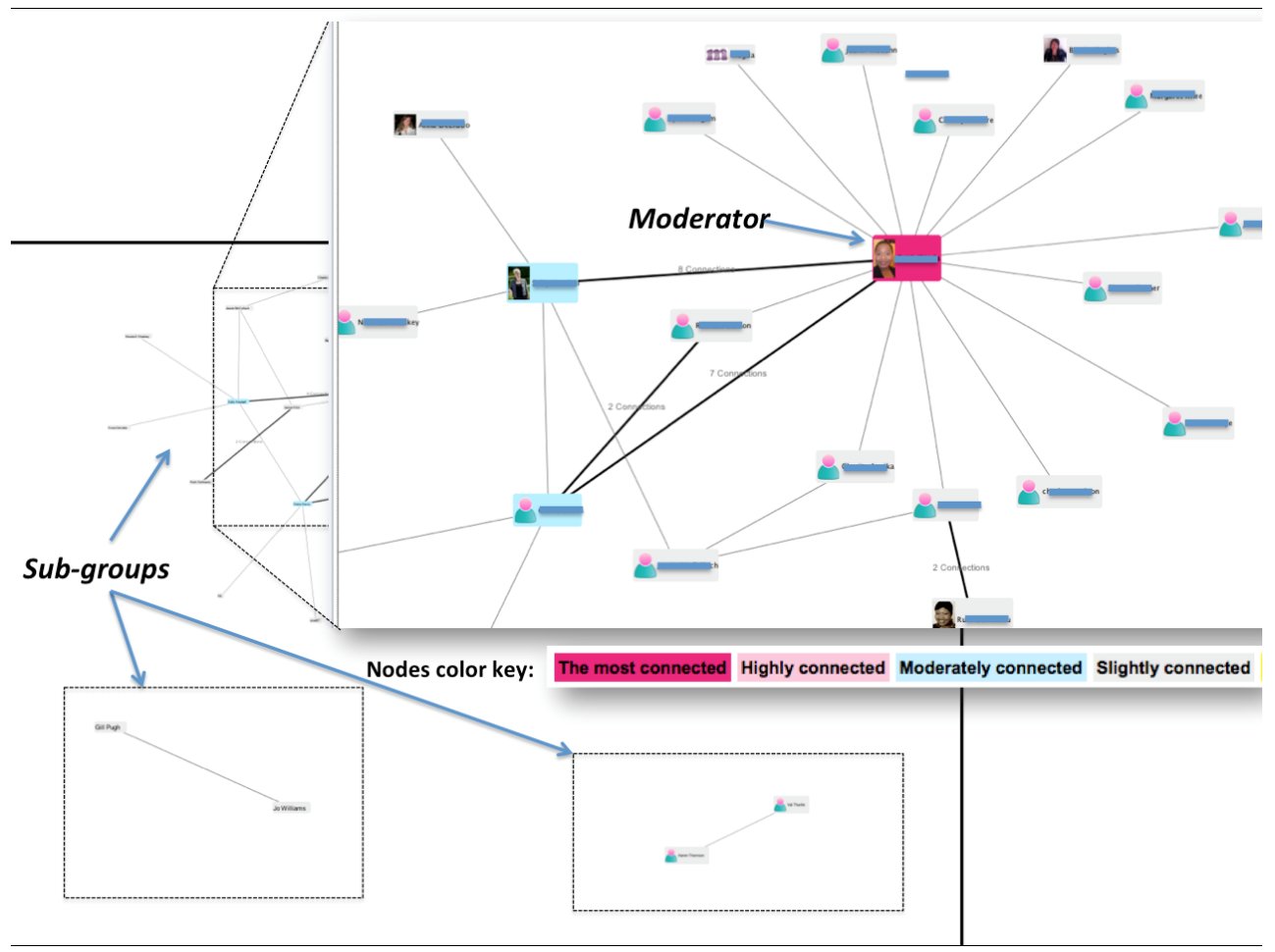

Figure 5. Social network of health visitors in the HV-CoP. 
cliques and sub-groups of health visitors still emerged.

Xie and Bradshaw [18] have noted that in large collaboration situations where multiple participants interact, the presence of moderation and guidance may not always be sufficient to support interaction. Studies have shown that people from different backgrounds and geographical spread may not easily connect with each other online, leading to the formation of loosely connected groups which can distort online interaction [32]. The presence of homophily, which is the degree to which participants of similar backgrounds will only hook up with each other, is noted to have a potentially limiting effect on online interaction among geographically distributed and diverse groups collaborating virtually.

The effect of homophily in the diversity of health visiting professionals on the HV-CoP encouraged some isolated networks to form as a result of connections around specialist topics, responding to only locally known colleagues or responding to only locality specific concerns. One group of health visitors for instance developed network the provision of domestic abuse services in their locality while another network of health visitors were concerned with discussing a very specialist set of discussions on speech and language.

In all, within highly professionally diverse and geographically spread groups, the degree to which a sense of community can be initiated and facilitated in order to make online interaction sustainable is highly dependent on facilitation. While moderation and offline events can provide a great deal of nurturing towards helping geographically dispersed and diverse professionals like health visitors to interact virtually, homophily increase the tendency of unconnected networks which in turn can produce less online interaction. How facilitators can employ other synchronous virtual activities and mechanisms to design tasks to help dispersed professionals with little prior connection to develop meaningful online interaction, remain poorly understood.

\subsection{The Influence of Topic Relevance on Online Interaction}

Online interaction may be related to how relevant participants find the topics governing their contributions in the virtual CoP. It has been suggested that the day to day topics that members may want to discuss as arising from their experiences may vary with the broad themes that may be used to specify how to construct contributions in a virtual CoP [33]. High topic irrelevance may produce low online interaction because participants' interests will not be enough to encourage interaction. Whereas, high topic relevance will facilitate more engaging online interaction among participants because the virtual CoP's topics mirror the discussions that directly draw on practitioners' experiences. The HV-CoP has 16 topic catego- ries (including Safe-guarding children, Parenting, Public health, and socio-economic determinants of health, Family Issues Professional issues, child development and use of technology) to guide participants' contribution. Topics in the HV-CoP were defined prior to designing the website by primarily exploring the major themes that arose in the health visiting literature rather than allowing topics emerge in the course of the community's life cycle. Table 4 shows that health visitors' contribution by topic categories varied with the highest interaction in topic categories like parenting, nutrition, family issues and professional issues in health visiting, while speech and language, ICT, and special needs and disability topics did not encourage as much contributions from the health visitors. Virtual CoPs for health practitioners must accommodate topics that bear most close semblance to issues that are most relevant to participant's daily practice and as much as possible aggregate less relevant topics under broader themes to enhance online interaction.

From the analysis, it is concluded that the right mix of topics in a virtual CoP is needed to drive online interaction. Virtual CoPs must comprise topics that are relevant enough to meet the common expectation especially among diverse health professionals, while less popular topics need to be melded so as to maintain online interaction among participants. A particular challenge for maintaining topic relevance among health professionals is that topics can quickly become outdated relative to policy, epidemiological or professional challenges at any point in time. Perhaps, encouraging health professionals themselves to influence what type of topics are provided for discussion in virtual spaces rather than implementing topics from a top-down approach may encourage higher topic relevance and better online interaction for health professionals.

Table 4. Contributions by topics in the HV-CoP.

\begin{tabular}{cc}
\hline Topics & Contributions by Health Visitors \\
\hline Building Community Capacity & 14 contributions \\
Child Development & 41 contributions \\
Family Issues & 68 contributions \\
Health Inequalities & 17 contributions \\
Healthy Child Program & 18 contributions \\
ICT in Health Visiting & 8 contributions \\
Infant Feeding/Child Nutrition & 69 contributions \\
Mental Health & 31 contributions \\
Parenting & 76 contributions \\
Visiting & 69 contributions \\
Public Health & 48 contributions \\
Professional Issues in Health & 37 contributions \\
Sleep & 29 contributions \\
\hline
\end{tabular}




\section{Conclusions}

The paper highlights how the benefits that virtual CoPs have offered to support knowledge sharing and networking for health practioners in professionally isolated circumstances can be drawn on to support joined up working and knowledge sharing among UK health visitors. The development of a Virtual CoP is especially timely since existing opportunities for collating expertise and professional opinion across health visiting are limited due to geo-graphical and professionally isolating circumstances. However, it is noted that while an effective virtual CoP can overcome many of the problems of professional isolation and improve the articulation of tacit experience as acceptable evidence, among health professionals like health visitors, other research has acknowledged that online interaction among practitioners is often low which causes many virtual CoPs not to achieve their potential. This paper examined how the membership characteristics of a virtual COP with particular consideration for number of participants, the relevance of the topics and geographic dispersion influenced online interaction of health visitors in a virtual CoP.

The findings of this study suggest that encouraging new members to visit or join the HV-CoP website can encourage more enthusiastic members over time to contribute new ideas and suggestions, has the potential to promote online interaction. It is, however, noted that beyond making a relationship between number of members, active participation and online interaction, there is the need to look beyond posting contributions and explore how reading and viewing the virtual CoP's pages may also be indicative of online interaction. Much discussion on online interaction tends to focus only on posting contributors at the expense of other activities like reading, marking comments as spam, voting on issues and liking comments. If these latter activities are to be considered, lurkers who engage with via reading of contributions may play a more crucial role than previously known in online interaction. The challenge remains how to devise strategies to measure forms of non-posting contributions such as those of lurkers as forms of online interaction.

The results in this study have also hinted at how engaging a moderator to seed discussions of interest and design tasks to encourage a sense of community among distributed groups can enhance how distributed health professionals engage and interact online. While offline events may play a crucial role in getting distributed groups to connect, it might be useful to explore other means of creating social awareness without necessarily promoting offline events. The challenges associated with face to face meets that are often at the heart of developing online $\mathrm{CoP}$ in the first place, may make offline events impractical. Future work exploring how synchronous technologies that incorporate teleconferencing and virtual meeting rooms can be employed to design tasks to foster and sustain online interaction among online participants may be useful. Lastly, the topics that are created to spur contributions in the virtual $\mathrm{CoP}$ must be relevant to member's daily practice in order to facilitate online interaction effectively.

Overall, understanding how all the structuring characteristics of a virtual CoP are collectively configured at a point in time is likely to give a more robust picture of online interaction among health professionals collaborating in virtual CoPs. In isolation from the entire structuring characteristics of a virtual $\mathrm{CoP}$, a singular set of membership characteristics alone can only give a snapshot rather than a complete overview of what can hinder or facilitate online interaction for health professionals. Nevertheless, although the discussions in this paper relate to the membership characteristics, it is acknowledged that the influence of size; topic relevance and geographic dispersion do interact with other demographic, organizational and technological contexts of the virtual CoP to inform what influences interaction. The findings for this paper, for in-stance, report on the influence of membership contexts in the early stages of development of a virtual $\mathrm{CoP}$ in its first year. This latter character of the age of the virtual CoP is a demographic characteristic that may also play a potential limiting role when considered with other characteristics, in influencing online interaction. Hew and Hara have identified that in the early stages of development of virtual CoPs online interaction is likely to be low because participants may lack the time to use the platform and will still be very unfamiliar with the technology of the community [34]. The competence of using ICT, whether management do or do not formally recognize and support virtual CoPs, the effect of people leaving the profession on online interaction and how to incentivize participants to interact online in the long term, remain questions that are equally relevant to consider for future discussions.

\section{Acknowledgements}

We acknowledge funding from the Burdett Trust for Nursing, the technological support of the Knowledge Media Institute of the Open University, Hertfordshire Partnership Community Trust, Bart's and London NHS Trust and The Institute of Health Visiting.

\section{REFERENCES}

[1] J. Gabbay, A. Le May, H. Jefferson, D. Webb, R. Lovelock, J. Powell and J. Lathlean, "A Case Study of Knowledge Management in Multiagency Consumer-Informed Communities of Practice: Implications for EvidenceBased Policy Development in Health and Social Services,” Health, Vol. 7, No. 3, 2003, pp. 283-310. 
[2] J. Lathlean and A. Le May, "Communities of Practice: An Opportunity for Interagency Working," Journal of Clinical Nursing, Vol. 11, No. 3, 2002, pp. 394-398. http://dx.doi.org/10.1046/j.1365-2702.2002.00630.x

[3] P. Gannon-Leary and E. Fontainha, "Communities of Practice and Virtual Learning Communities: Benefits, Barriers and Success Factors,” eLearning Papers, No. 5, 2007.

[4] S. Jarvis-Selinger, A. Armstrong, S. Mehta, E. Campion and K. Black, “Orthopaedic Educators' Electronic Community of Practice: Development of a Supportive Online Learning Environment for Academic Orthopedic Surgeons,” In: K. Ho, et al., Eds., Technology Enabled Knowledge Translation for eHealth, 2012, Springer, New York, pp. 117-131. http://dx.doi.org/10.1007/978-1-4614-3495-5 8

[5] C. Urquhart, A. Yeoman and S. Sharp, "NeLH Communities of Practice Evaluation Report," Prepared for NeLH team, NHS Authority, 2002.

[6] R. K. Valaitis, N. Akhtar-Danesh, F. Brooks, S. Binks and D. Semogas, "Online Communities of Practice as a Communication Resource for Community Health Nurses Working with Homeless Persons," Journal of Advanced Nursing, Vol. 67, No. 6, 2011, pp. 1273-1284. http://dx.doi.org/10.1111/j.1365-2648.2010.05582.x

[7] J. Sandars, "Online Communities of Practice for Healthcare Professionals: When Hype Meets Reality,” Undated.

[8] G. Singh, M. McPherson and J. Sandars, "Continuing Professional Development through Reflexive Networks: Disrupting Online Communities of Practice,” University of Stirling, Stirling, 2012.

[9] M. Sharratt and A. Usoro, "Understanding KnowledgeSharing in Online Communities of Practice," Electronic Journal on Knowledge Management, Vol. 1, No. 2, 2003, pp. 187-196.

[10] A. Ardichvili, V. Page and T. Wentling, "Motivation and Barriers to Participation in Virtual Knowledge-Sharing Communities of Practice," Journal of Knowledge Management, Vol. 7, No. 1, 2003, pp. 64-77. http://dx.doi.org/10.1108/13673270310463626

[11] L. Dubé, A. Bourhis and R. Jacob, “Towards a Typology of Virtual Communities of Practice,” Interdisciplinary Journal of Information, Knowledge, and Management, Vol. 1, No. 1, 2006, pp. 69-93.

[12] E. Ferlie, T. Crilly, A. Jashapara and A. Peckham, "Knowledge Mobilisation in Healthcare: A Critical Review of Health Sector and Generic Management Literature,” Social Science \& Medicine, Vol. 74, No. 8, 2012, pp. 1297-1304. http://dx.doi.org/10.1016/j.socscimed.2011.11.042

[13] S. Cowley, K. Whittaker, A. Grigulis, M. Malone, S. Donetto, H. Wood, E. Morrow and J. Maben, "Why Health Visiting? A Review of the Literature about Key Health Visitor Interventions, Processes and Outcomes for Children and Families," National Nursing Research Unit, King's College London, 2013.

[14] Department of Health, “A Health Visiting Career,” London, 2012.

[15] A. M. Houston and S. Cowley, “An Empowerment Ap- proach to Needs Assessment in Health Visiting Practice," Journal of Clinical Nursing, Vol. 11, No. 5, 2002, pp. 640-650. http://dx.doi.org/10.1046/j.1365-2702.2002.00637.x

[16] A. De Liddo, B. S. S. McAndrew Patrick and R. Farrow, "The Open Education Evidence Hub: A Collective Intelligence Tool for Evidence Based Policy,” Joint OER12 and Open Course Ware Consortium Global 2012 Conference, Cambridge, 2012.

[17] K. McCartney, D. Hooker, J. Cordeiro, H. N. Lauscher and K. Ho, "Practical Considerations in Building an Electronic Community of Practice for Health Care: Lessons from the Literature,” In: K. Ho, S. J. Selinger, H. N. Lauscher, J. Cordeiro and R. Scott, Eds., Technology Enabled Knowledge Translation for eHealth, Springer, New York, 2012, pp. 75-90.

http://dx.doi.org/10.1007/978-1-4614-3495-5_6

[18] K. Xie and A. C. Bradshaw, "Using Question Prompts to Support Ill-Structured Problem Solving in Online Peer Collaborations," International Journal of Technology in Teaching and Learning, Vol. 4, No. 2, 2008, pp. 148-165.

[19] M. Fontaine, "Keeping Communities of Practice Afloat," Knowledge Management Review, Vol. 4, No. 4, 2001, pp. 16-21.

[20] L. C. Li, J. M. Grimshaw, C. Nielsen, M. Judd, P. C. Coyte and I. D. Graham, "Use of Communities of Practice in Business and Health Care Sectors: A Systematic Review," Implementation Science, Vol. 4, No. 27, 2009, p. 16.

[21] H. Tarmizi, G. J. de Vreede and I. Zigurs, “A Facilitators' Perspective on Successful Virtual Communities of Practice,” Citeseer, 2007.

[22] C. Errey, "Building Online Social Communities: Helping Your Members Cross the Observer/Participant Barrier," Undated, pp. 1-7.

[23] A. L. Blanchard and M. L. Markus, "The Experienced Sense of a Virtual Community: Characteristics and Processes,” ACM SIGMIS Database, Vol. 35, No. 1, 2004, pp. 64-79. http://dx.doi.org/10.1145/968464.968470

[24] X. Wang and Y. Yu, "Classify Participants in Online Communities," Social and Information Networks, Vol. 4, No 1, 2012, 13 p.

[25] J. Nielsen, "Participation inequality: Encouraging More Users to Contribute,” Jakob Nielsen's Alertbox, October 9, 2006.

[26] K. F. Hew and N. Hara, "Knowledge Sharing in Online Environments: A Qualitative Case Study,” Journal of the American Society for Information Science and Technology, Vol. 58, No. 14, 2007, pp. 2310-2324. http://dx.doi.org/10.1002/asi.20698

[27] A. P. Rovai, "Building Sense of Community at a Distance," The International Review of Research in Open and Distance Learning, Vol. 3, No. 1, 2002.

[28] M. M. Wasko and S. Faraj, "Why Should I Share? Examining Social Capital and Knowledge Contribution in Electronic Networks of Practice,” MIS Quarterly, Vol. 29, No. 1, 2005, pp. 35-57.

[29] J. Koh, Y. G. Kim, B. Butler and G. W. Bock, "Encour- 
aging Participation in Virtual Communities," Communications of the ACM, Vol. 50, No. 2, 2007, pp. 68-73. http://dx.doi.org/10.1145/1216016.1216023

[30] B. Malby and K. Mervyn, "Social Networks: An Additional Brief Literature Review for the Health Foundation," Centre for Innovation in Health Management, University of Leeds, 2012.

[31] G. Ranmuthugala, F. C. Cunningham, J. J. Plumb, J. Long, A. Georgiou, J. I. Westbrook and J. Braithwaite, "A Realist Evaluation of the Role of Communities of Practice in Changing Healthcare Practice,” Implementation Science, Vol. 6, 2011, p. 49. http://dx.doi.org/10.1186/1748-5908-6-49
[32] R. Helms, "Redesigning communities of Practice Using Knowledge Network Analysis," 2007.

[33] L. Dubé, A. Bourhis and R. Jacob, “The Impact of Structuring Characteristics on the Launching of Virtual Communities of Practice," Journal of Organizational Change Management, Vol. 18, No. 2, 2005, pp. 145-166. http://dx.doi.org/10.1108/09534810510589570

[34] K. F. Hew and N. Hara, "Identifying Factors That Encourage and Hinder Knowledge Sharing in a Longstanding Online Community of Practice," Journal of Interactive Online Learning, Vol. 5, No. 3, 2006, pp. 297-316. 